\title{
A RESPONSABILIDADE SOCIAL NO BRASIL: o caso da cooperativa COCAMAR.
}

\author{
1- Fernando Serra \\ Universidade do Sul de Santa Catarina - Unisul \\ fernando.serra@unisul.br>
}

\author{
3- Wagner Teixeira \\ Universidade do Sul de Santa Catarina - Unisul \\ wagnerteixeira2001@yahoo.com.br
}

\author{
2- Manuel Portugal Ferreira \\ Instituto Politécnico de Leiria - IPL \\ portugal@estg.ipleiria.pt
}

Diego Maganhotto Coraiola - Editor

\section{RESUMO}

Neste trabalho foi analisado como a responsabilidade social e ambiental se inserem na estratégia da Cooperativa Agroindustrial de Maringá - COCAMAR, Paraná. O estudo do caso é apoiado em dados primários e secundários, em particular em entrevistas com os colaboradores da COCAMAR diretamente envolvidos nos programas de responsabilidade social e ambiental. Estão ilustradas as mudanças organizacionais e dos valores culturais da cooperativa que suportam o leque de projetos sociais desenvolvidos junto à comunidade interna e externa. Concluiu-se com a análise de como a responsabilidade social corporativa pode se inserir na estratégia das cooperativas, implicações para a teoria e a prática e sugestão de investigações futuras. No caso da COCAMAR a responsabilidade social faz parte de suas ações estratégicas o que confere com a visão moderna de cooperativas. Adicionalmente a empresa participa de ações deste tipo, mas possui projetos próprios além de envolver seus cooperados. Mesmo durante períodos de dificuldade e apesar da competição acirrada, manteve suas iniciativas de responsabilidade social. Entretanto, ainda não possui qualquer certificação em normas relacionadas ou se utiliza adequadamente de ações de marketing para potencializar a imagem.

\section{Palavras-Chave}

Responsabilidade social. Responsabilidade ambiental. Estratégia empresarial. Cooperativas.

\section{ABSTRACT}

In this work we check how social and environmental responsibility are inserted in Cooperativa Agroindustrial de Maringá - COCAMAR, Paraná. The case study is supported in primary and secondary data. It is also supported by interviews with COCAMAR employees directly involved in social and environmental programs. We show the organizational changes and cultural values of the Cooperative that supports the range of social projects developed with the internal and external community. We conclude with an analysis of how corporate social responsibility is inserted at company's strategy, implications for practice and theory, as well as suggestions for future investigations. Social responsibility is part of the strategic actions of COCAMAR what agrees with the modern vision of cooperatives. Even during hard times and despite of strong competition the company kept its social responsibility initiatives. The company does not have any social responsibility related certification. Also do not take advantage of marketing actions for image potential.

Keywords

Corporate social responsibility. Environmental responsibility. Corporate strategy. Cooperatives. 


\section{Introdução}

Nos últimos anos, o interesse dos administradores pelo tema Responsabilidade Social Corporativa tem crescido substancialmente. Devido ao agravamento de problemas sociais e ambientais por todo o planeta, desemprego, exclusão, poluição, exaustão de recursos naturais, e à dificuldade dos governos de solucioná-los, as forças da sociedade civil procuram formas de pressionar as empresas a adotar uma postura socialmente responsável na condução dos seus negócios. Há uma crescente preocupação coletiva em relação ao meio ambiente e à complexidade das atuais demandas sociais que a comunidade repassa às organizações induzindo a um novo posicionamento por parte dos empresários. As empresas conscientizam-se, assim, da importância de considerar os interesses de outros grupos (stakeholders), não só dos acionistas, afetados por sua atuação: fornecedores, empregados, comunidade, consumidores, sociedade e meio ambiente. É a própria noção de sucesso empresarial que é questionada, deixando de ser exclusivamente orientada para os resultados econômico-financeiros, para exigir também resultados sociais e ambientais, dentro de uma perspectiva de desenvolvimento sustentável (MAYNARD JÚNIOR; MEHRTENS, 1993).

A atuação socialmente responsável pelas empresas passa a fazer parte da sua estratégia. Muitos empresários e administradores chegaram à conclusão de que não basta só visar lucros nem ser competitivos e eficientes para garantir o sucesso empresarial. Uma atuação socialmente responsável contribui para maior competitividade, melhor ambiente de trabalho, mais motivador e eficiente, melhor imagem institucional positiva e melhor relacionamento com os parceiros de negócio (MARTINELLI, 1997; ASHLEY; COUTINHO; TOMEI, 2000). Assim, apesar de o conceito de responsabilidade social ser relativamente recente no meio empresarial brasileiro, tem conquistado um maior número de empresas no Brasil. Estes gestores são profissionais sensíveis, ousados e com visão de futuro que reforçam a aposta em projetos/programas sociais e que, assim, contribuem para mudar a realidade social do país.

A Responsabilidade Social Corporativa (RSC) está entre as tendências mais importantes que influenciam a teoria e a prática da administração na passagem do século XXI. A atuação baseada em princípios éticos e a busca de qualidade nas relações são manifestações da RSC. Esta, é hoje, um fator de legitimidade social e um importante atributo positivo para a imagem pública e reputação das empresas. É uma exigência cada vez mais presente a adoção de padrões de conduta ética que valorizem o ser humano, a sociedade e o meio ambiente (HART; CHRISTENSEN, 2002; STIGLITZ, 2002; LONDON; HART, 2004). Mas, também contribui para as empresas se diferenciarem, para além de fatores como a qualidade dos produtos ou diferenciais nos preço. Na busca de diferenciação, a tendência mundial é a de consumidores se interessarem pelo comportamento das empresas e darem preferência às socialmente responsáveis, uma vez que a adoção de um comportamento que ultrapassa as exigências legais agrega valor à imagem da empresa, aumentando o vínculo que seus consumidores e clientes estabelecem com ela (RODRIGUEZ; RICART; SANCHEZ, 2002; PRAHALAD; HART, 2002). As empresas brasileiras ainda precisam efetuar mudanças profundas em várias dimensões dos seus negócios.

Uma empresa socialmente responsável é aquela que, além de ser ética nos seus negócios, preocupa-se com questões tais como: a não utilização de mão-de-obra infantil, saúde de seus funcionários, não utilização de trabalhos forçados, segurança no trabalho, liberdade de associação e negociação coletiva, não discrimina seus funcionários nem a sociedade em geral, respeita horário de trabalho para os colaboradores, possui preocupação com questões ambientais e um sistema de gestão coerente. A empresa deve, ainda, investir na educação e no progresso de seus funcionários, na saúde, na alimentação. Isto é, a gestão empresarial não pode limitar a sua preocupação aos interesses dos acionistas, mas deve considerar também outros stakeholders. Assim, a empresa necessita buscar a excelência através da qualidade, das relações com a comunidade e da sustentabilidade econômica, social e ambiental da sua atuação. Uma empresa que cumpre o seu papel social atrai mais consumidores, investe na sociedade e no seu próprio futuro.

Apesar dos esforços atuais de empresas e acadêmicos, ainda sabe-se muito pouco sobre os reais benefícios de uma atuação socialmente responsável. Atualmente se fala da participação de empresas em atividades sociais, pelas quais as empresas demonstram a preocupação com a produção, mas também com a buscar do bem-estar social através da preocupação com a valorização do homem, do meio ambiente e da cultura. Não se sabe como esses elementos determinam o sucesso mercadológico. Parece certo que a eficiência empresarial não é só "fazer as coisas bem", mas "fazer as coisas boas", segundo princípios éticos. Mas, a lacuna atual mantém-se e é ainda pouco claro como a RSC é um elemento da estratégia corporativa.

Neste trabalho foi analisado como a responsabilidade social e ambiental está inserida 
na estratégia de uma cooperativa agrícola - a COCAMAR - Cooperativa Agroindustrial de Maringá, Paraná. O problema que se estabelece: como a responsabilidade social e ambiental estão inseridas na estratégia das cooperativas? E, em particular, como a responsabilidade social corporativa se insere na estratégia da COCAMAR Cooperativa Agroindustrial de Maringá, Paraná. Por meio dos resultados da pesquisa bibliográfica são identificados os atributos relacionados a como responsabilidade social está inserida na estratégia da COCAMAR, direcionando-a assim a uma postura socialmente responsável. $\mathrm{Na}$ seqüência são apresentados conceitos sobre responsabilidade social, sua evolução, a responsabilidade social no Brasil, suas ações, indicadores de avaliação da responsabilidade social e seu fator competitivo. É apresentada também a relação entre desenvolvimento sustentável, ética e responsabilidade social.

O restante do trabalho está organizado em quatro partes. Após o referencial teórico, é avançado conjunto de proposições baseadas na teoria existente. Na terceira parte estuda-se o caso proposto; para o que descreve-se a COCAMAR, as fontes dos dados recolhidos e resultados. Apresenta-se, ainda, os antecedentes estratégicos da COCAMAR, onde foram investigadas as mudanças organizacionais e seus valores culturais durante o período de 1990 - 2005. Conclui-se com uma análise integrada da teoria e do caso de estudo, implicações e um conjunto de recomendações para trabalhos de investigação futuros.

\section{A Responsabilidade Social: Revisão da Literatura}

\subsection{Fundamentos Históricos da Responsabilidade Social}

A idéia de as empresas serem socialmente responsáveis não é nova nem uma moda passageira (ASHLEY, 2002). É um valor que foi crescendo, evoluindo, tomando corpo até adquirir uma dimensão universal (ver por exemplo, CHEIT, 1964) Já em 1920, Henry Ford defendia que as empresas tinham de participar no bem estar coletivo.

As origens e os exemplos de uma política socialmente responsável pelas empresas são antigos e estão, por vezes, ligados a credos religiosos. Os QUAKERS, membros de uma comunidade protestante criada em 1.747, na Inglaterra, e que foram proeminentes na economia detendo empresas como o Barclays, Lloyds, Price Waterhouse, Cadbury, entre outras, ficaram conhecidos por terem sido os primeiros a recusar a indústria de guerra e escravatura. Baseavam os seus valores na integridade, respeito dos contratos e dos preços fixados e na atenção especial que davam à higiene e segurança no trabalho (ASHLEY, 2002). Em 1908, nos Estados Unidos, o conselho federal das igrejas emite um documento onde se manifesta a favor de direitos iguais e de justiça para todos, da abolição do trabalho infantil, contra a discriminação, a exploração dos trabalhadores, e pela diminuição das horas de trabalho, a proteção dos trabalhadores no trabalho, entre outros (OLIVEIRA NETO, 1999). O primeiro fundo de investimento socialmente responsável, denominado Pioneer Fund, tem também origem religiosa. Lançado em 1928 pela igreja Evangelista americana, opunha-se ao consumo do álcool e do tabaco (OLIVEIRA NETO, 1999).

Em outros casos foi a exigência dos consumidores e comunidades por uma nova postura das empresas, que muitas vezes chega a ser confundida com a luta pelos direitos cívicos (OLIVEIRA NETO, 1999) a liderar o desenvolvimento da responsabilidade social. Por exemplo, em 1955, a empresa de transportes públicos de Montgomery, nos EUA, foi alvo de um boicote por praticar discriminação racial (ASHLEY, 2002). Mas, é nos finais dos anos sessenta, que os movimentos dos consumidores, por uma nova postura das empresas, tomam posição de uma forma mais sistemática e generalizada. Organizam boicotes aos serviços ligados à guerra e ações de força contra algumas empresas como, por exemplo, à General Motors, impondo a fabricação de automóveis mais seguros (ASHLEY, 2002).

Atualmente, a sociedade de informação contemporânea, a receptividade da imprensa às denuncias feitas pelas organizações de consumidores e a globalização impulsionam as empresas a serem socialmente responsáveis. Notícias da violação dos direitos humanos numa fábrica na Ásia chegam aos consumidores finais quase imediatamente e estes podem tomar uma posição (ASHLEY, 2002). Não é de estranhar o surgimento dos primeiros esboços de relatórios de responsabilidade social (OLIVEIRA NETO, 1999). Hoje, as grandes multinacionais elaboram relatórios de responsabilidade social, onde expressam os seus compromissos e relação ao ambiente, aos colaboradores e à comunidade. Freqüentemente, é possível encontrar nas multinacionais traduções dos seus códigos de boas praticas, na língua do país onde estão implantadas, e dos seus procedimentos definidos a nível mundial (ASHLEY, 2002). Este esforço empresarial é complementado pelo esforço institucional internacional.

No Brasil, as primeiras discussões sobre responsabilidade social das empresas surgiram no inicio dos anos 70, tendo como protagonista a Associação dos Dirigentes Cristãos de Empresas (ADCE), cujo objetivo inicial era promover o debate 
sobre o balanço social (ASHLEY; COUTINHO; TOMEI, 2000). Nos anos 90, o movimento de valorização as responsabilidade social empresarial ganhou forte impulso na década de 90, através da ação de entidades não governamentais, institutos de pesquisa e empresas sensibilizadas para a questão. O trabalho do Instituto Brasileiro de Análises Sociais e Econômicas - IBASE na promoção do Balanço Social é uma de suas expressões e tem logrado progressiva repercussão (ASHLEY, 2002). O quadro institucional brasileiro também se tem vindo a fortalecer quer por via da atuação do Estado, quer pela iniciativa da comunidade e hoje encontra-se organizações como a Fundação Abrinq pelos Direitos da Criança, Instituto Ethos de Empresa e Responsabilidade Social, etc. Além da certificação de qualidade e de adequação ambiental, como as normas ISO, por centenas de empresas brasileiras.

Assim, aceita-se que atualmente, a responsabilidade social se baseia na noção de que as corporações possuem a obrigação de trabalhar para a melhoria do bem-estar social (FREDERICK, 1994). Esta é fundada em duas premissas centrais: (1) existe um contrato entre a organização e a sociedade, que funciona como um veículo por meio do qual o comportamento dos negócios é posto em conformidade com os objetivos da sociedade; (2) os negócios desempenham o papel de agentes morais dentro da sociedade, refletindo e reforçando seus valores (WARTICK; COCHRAM, 1985; ASHLEY, 2002).

\subsection{A Responsabilidade Social}

As transformações socioeconômicas dos últimos 20 anos têm afetado profundamente o comportamento de empresas até então acostumadas à pura e exclusiva maximização do lucro. Com o surgimento de novas demandas e maior pressão por transparência nos negócios, empresas se vêem forçadas a adotar uma postura mais responsável em suas ações.

A responsabilidade social pode ser definida como o compromisso que uma organização deve ter para com a sociedade, expresso por meio de atos e atitudes que a afetem positivamente, de modo amplo, ou a alguma comunidade, de modo especifico, agindo pro ativamente e coerentemente no que tange a seu papel especifico na sociedade e a sua prestação de contas para com ela. A organização, nesse sentido, assume obrigações de caráter moral, além das estabelecidas em lei, mesmo que não diretamente vinculadas a suas atividades, mas que possam contribuir para o desenvolvimento sustentável dos povos.
Srour (1988) argumenta que uma empresa socialmente responsável é aquela que mostra pronta disposição para aceitar as conseqüências de seus atos e apresenta senso de obrigação tanto para com o seu público interno (os seus colaboradores) quanto para com a comunidade externa. No entanto o autor define empresa responsável como aquela em que a sociedade pode confiar e também possua uma postura ética.

De acordo com Melo Neto e Froes (1999) e Lunhein (2002) a responsabilidade social inclui questões relacionadas a direitos humanos, trabalho, relações comunitárias e relações entre fornecedores e consumidores; pelo que a empresa socialmente responsável cria valores éticos e contribui para a melhoria das condições sociais das pessoas (empregados e de suas famílias, da comunidade local e da sociedade como um todo) afetadas por suas ações. E, é neste contexto que a responsabilidade social extravasa para outros agentes. Como sugerem Melo Neto e Froes (1999), já é possível encontrar sinais de que o empresariado brasileiro se tem inclinado para a criação de entidades junto ao setor solidário, com vista a auxiliar os mais carentes, numa demonstração de maior consciência social.

Entre as várias conceituações e abordagens, Duarte e Dias (1986) resumem três aspectos essenciais na doutrina de responsabilidade social: (a) ampliação do alcance da responsabilidade da empresa, que não mais se limita ao grupo de acionistas; (b) mudança e natureza dessas responsabilidades, visto que ultrapassam o âmbito da prescrição legal, envolvendo também o da moral ditado pela ética; e (c) a adequação às demandas sociais, num dado contexto socioeconômico. Ou, de acordo com Srour (1988, p. 294), a responsabilidade social dobra-se a múltiplas exigências:

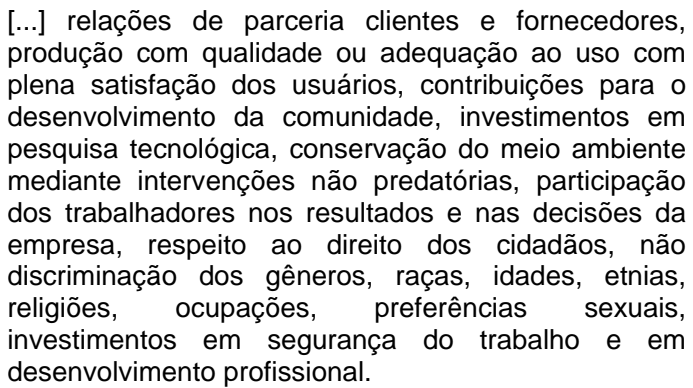

Carrol (1991) propõe uma definição onde aponta quatro faces ou dimensões para a responsabilidade social: econômica, legal, ética e filantrópica (Quadro 1). No quadro constam descrições dos significados das quatro dimensões. As quatro dimensões da responsabilidade social estão intimamente relacionadas, cada uma não existindo isoladamente das outras, e o conjunto delas significa a adoção da responsabilidade social. 
Quadro 1 - Significado das quatro dimensões de Carrol da responsabilidade social

\begin{tabular}{ll}
\hline \multicolumn{1}{c}{ Dimensões } & \multicolumn{1}{c}{ Significado } \\
Econômica & $\begin{array}{l}\text { A dimensão econômica incluiria as obrigações da empresa em ser produtiva e lucrativa, além de atender às } \\
\text { expectativas dos acionistas de obter retorno sobre o investimento. Todos os outros papeis dos negócios são } \\
\text { atributos derivados desse pressuposto fundamental. }\end{array}$ \\
\hline \multirow{2}{*}{ Legal } & $\begin{array}{l}\text { A dimensão legal requer que o negocio acrescente à sua missão econômica o respeito às leis e aos } \\
\text { regulamentos. A sociedade espera que os negócios ofereçam produtos dentro das normas de segurança e } \\
\text { obedeçam a regulamentações governamentais. }\end{array}$ \\
\hline \multirow{3}{*}{ Ética } & $\begin{array}{l}\text { A dimensão ética leva em consideração princípios e padrões que definem a conduta aceitável determinada por } \\
\text { público, órgãos regulamentadores, grupos privados interessados, concorrentes e a própria organização. A } \\
\text { tomada de decisões deve ser feita considerando-se as conseqüencias de suas ações, honrando o direito dos } \\
\text { outros, cumprindo deveres e evitando prejudicar terceiros. }\end{array}$ \\
\hline \multirow{2}{*}{ Filantrópica } & $\begin{array}{l}\text { A dimensão filantrópica prevê que o negocio deve estar envolvido com a melhoria da sociedade por meio das } \\
\text { responsabilidades legal, ética e econômica, bem como com a adoção de praticas filantrópicas. A dimensão } \\
\text { filantrópica preve atividades que são guiadas pelo desejo dos negócios em se engajar em papeis sociais não }\end{array}$ \\
\hline Fonte: Carrol, 1991; & legalmente obrigatórios, mas que estão se tornando cada vez mais estratégicos.
\end{tabular}

Melo Neto e Froes (2001) comentam que para a empresa ser socialmente responsável não basta apoiar o desenvolvimento da comunidade e preservar o meio ambiente, antes são necessários estágios como: o apoio ao desenvolvimento da comunidade onde atua; a preservação do meio ambiente; o investimento no bem-estar dos funcionários e seus dependentes e também em um ambiente de trabalho agradável; as comunicações transparentes; o retorno aos acionistas; a sinergia com os parceiros; a satisfação dos clientes e/ou consumidores. Estes estágios direcionam o processo de gestão empresarial para o fortalecimento da dimensão social da empresa.

\subsection{O Público Interno e a Comunidade}

Segundo Melo Neto e Froes (1999) o exercício da cidadania empresarial pressupõe uma atuação eficaz da empresa em duas dimensões: a gestão da responsabilidade social interna e a gestão da responsabilidade social externa. A responsabilidade social interna focaliza o público interno da empresa, seus empregados e seus dependentes. O objetivo é motivá-los para um melhor desempenho, criar um ambiente agradável de trabalho e contribuir para o seu bem-estar. Os ganhos em produtividade, pelo acréscimo de dedicação, empenho e lealdade, são consideráveis para a empresa. A responsabilidade social externa tem como foco a comunidade mais próxima da empresa ou local onde ela está inserida. Dessa forma, atuando em ambas as dimensões, a empresa exerce a sua cidadania empresarial e adquire o seu status de "empresa cidadã".

A abordagem destes autores é fortemente baseada na teoria dos stakeholders (ver por exemplo FREEMAN, 1984), um das teorias seminais para o tema de RSC. Ou seja, stakeholders como quaisquer organizações ou indivíduos que influenciem ou sejam influenciados pela organização em questão (SERRA; TORRES; TORRES, 2002). Nesta abordagem, a RSC deve considerar os empregados e seus dependentes também.

De acordo com Melo Neto e Froes (1999) as ações de gestão interna de responsabilidade social interna compreendem os investimentos no bemestar dos empregados e seus dependentes (programas de remuneração e participação nos resultados, assistência médica, social, odontológica, alimentar e de transporte); e os investimentos na qualificação dos empregados (programas internos de treinamento e capacitação e programas de financiamento de cursos externos, regulares ou não, realizados por seu funcionário com vistas a sua maior qualificação profissional e obtenção de escolaridade mínima).

O exercício da responsabilidade social externa corresponde ao desenvolvimento de ações sociais empresariais que beneficiam a comunidade. Estas ações podem ser realizadas através de doações de produtos, equipamentos e materiais em geral, transferência de recursos em regime de parceria para órgãos públicos e ONGs, prestação de serviços voluntários para a comunidade pelos funcionários da empresa, aplicações de recursos em atividades de preservação do meio ambiente, geração de empregos, patrocínio de projetos sociais do governo e investimentos diretos em projetos sociais criados pela própria empresa (MELO NETO; FROES, 1999). O quadro 2 apresenta os conceitos . 
Quadro 2 - Responsabilidade social interna e externa

\begin{tabular}{|c|l|l|}
\hline & \multicolumn{1}{|c|}{ Responsabilidade Social Interna } & Responsabilidade Social Externa \\
\hline Foco & Público Interno (empregados e seus dependentes) & Comunidade \\
\hline \multirow{4}{*}{ Áreas de Atuação } & $\begin{array}{l}\text { Educação } \\
\text { Salários e Benefícios } \\
\text { Assistência Médica, Social e Odontológica }\end{array}$ & $\begin{array}{l}\text { Educação } \\
\text { Saúde } \\
\text { Assistência Social } \\
\text { Ecologia }\end{array}$ \\
\hline \multirow{2}{*}{ Instrumentos } & Programas de RH & $\begin{array}{l}\text { Doações } \\
\text { Programas de Voluntariado } \\
\text { Parcerias } \\
\text { Programas e Projetos Sociais }\end{array}$ \\
& & $\begin{array}{l}\text { Retorno Social Propriamente dito } \\
\text { Retorno de Imagem } \\
\text { Retorno Publicitário } \\
\text { Retorno para os Acionistas }\end{array}$ \\
\hline
\end{tabular}

Fonte: Melo Neto e Froes, 1999.

É neste contexto que, de acordo com Melo Neto e Froes (2001), o exercício da responsabilidade social tem dois focos distintos: os projetos sociais e as ações comunitárias. Os projetos sociais são empreendimentos voltados para a busca de soluções de problemas sociais que afligem populações e grupos sociais numerosos ou em situações de alto risco. Tais problemas, se negligenciados ou enfrentados sem a determinação exigida pelas circunstâncias, agravam-se com o tempo e demandam soluções imediatas e de médio e longo prazo. As ações comunitárias correspondem à participação da empresa em programas e campanhas sociais realizadas pelo governo, entidades filantrópicas e comunitárias ou por ambas. Tal participação ocorre por meio de doações, ações de apoio e trabalho voluntário de seus empregados. Nas ações comunitárias, a empresa insere-se na comunidade por meio de transferência e repasse de recursos para entidades assistenciais e comunitárias.
Os benefícios da prática da responsabilidade social para as empresas são diversos e contribuem para o bom desempenho e imagem da empresa Pagliano et al. (1999). Pode-se destacar, por exemplo, a proteção e fortalecimento da imagem da marca, reputação e credibilidade; o contributo para a diferenciação dos concorrentes; a fidelização dos clientes; a proteção contra ações negativas dos consumidores, nomeadamente evitando potenciais boicotes futuros ao consumo; a atração e manutenção dos melhores talentos; a atração de investidores individuais e institucionais (ver, por exemplo, MARTINELLI, 1997).

\subsection{Responsabilidade Social Como Fator Competitivo}

O conceito de responsabilidade social e sua relação com a competitividade e com a estratégia foram variando ao longo do tempo. O quadro 3 apresenta a seguir de forma sintética esta evolução.

\begin{tabular}{|c|c|c|}
\hline Autor & Perspectiva Teórica & Argumento chave ou resultado \\
\hline $\begin{array}{l}\text { Friedman } \\
(1970)\end{array}$ & Teoria da Agência & $\begin{array}{l}\text { RSC é indicada como um comportamento dos gestores que reduz } \\
\text { os ganhos da empresa. }\end{array}$ \\
\hline $\begin{array}{l}\text { Freeman } \\
(1984)\end{array}$ & Teoria dos Stakeholders & $\begin{array}{l}\text { Os gestores precisam ajustar suas decisões para outros públicos, } \\
\text { e não só os acionistas. }\end{array}$ \\
\hline $\begin{array}{l}\text { Donaldson e } \\
\text { Davies (1991) }\end{array}$ & Stewardship Theory & $\begin{array}{l}\text { Existe uma obrigação moral do gestores em fazer o que é certo, } \\
\text { independentemente de como estas decisões venham afetar o } \\
\text { desempenho organizacional. }\end{array}$ \\
\hline $\begin{array}{l}\text { Donaldson e } \\
\text { Preston (1995) }\end{array}$ & Teoria dos Stakeholders & Exploraram as dimensões éticas e morais da teoria. \\
\hline Jones (1995) & Teoria dos Stakeholders & $\begin{array}{l}\text { Empresas que se envolvem em transações confiança e } \\
\text { cooperação com os stakeholders colhem benefícios deste } \\
\text { comportamento. }\end{array}$ \\
\hline Hart (1995) & $R B V$ & $\begin{array}{l}\text { Para algumas companhias a responsabilidade social e ambiental } \\
\text { constitui-se em fonte de vantagem competitiva. }\end{array}$ \\
\hline $\begin{array}{c}\text { Jennings e } \\
\text { Zandbergen (1995) }\end{array}$ & Teoria Institucional & $\begin{array}{l}\text { As instituições têm um papel importante em estabelecer um } \\
\text { consenso interno para estabelecer uma organização } \\
\text { ecologicamente sustentável. }\end{array}$ \\
\hline Baron (2001) & Teoria da Firma & O uso da RSC atrai consumidores socialmente responsáveis. \\
\hline $\begin{array}{l}\text { McWilliams e } \\
\text { Siegel (2001) }\end{array}$ & Teoria da Firma & $\begin{array}{l}\text { O nível de RSC da empresa pode ser determinado pelo custo- } \\
\text { benefício. }\end{array}$ \\
\hline $\begin{array}{l}\text { McWilliams, } \\
\text { Siegel e Wright } \\
(2006)\end{array}$ & $R B V$ & $\begin{array}{l}\text { RSC quando suportadas por estratégias políticas podem ser } \\
\text { usadas para conseguir vantagem competitiva. }\end{array}$ \\
\hline $\begin{array}{l}\text { Waldman et al. } \\
\text { (2006) }\end{array}$ & $\begin{array}{l}\text { Teoria da Firma / Teoria da Liderança } \\
\text { Estratégica }\end{array}$ & Certos aspectos da liderança aumentam a propensão para a RSC. \\
\hline
\end{tabular}


Com a evolução da relação do conceito, RSC passou a poder ser uma fonte de vantagem competitiva das organizações. A responsabilidade social, assumida de forma consistente e inteligente pela empresa, pode contribuir de forma decisiva para a sustentabilidade e o desempenho empresarial. Os efeitos positivos denotam-se num clima de simpatia para a imagem da empresa, numa reputação de empresa comprometida com a busca de soluções para os problemas sociais da comunidade. Os produtos, serviços e marca ganham visibilidade e aceitação, fazendo com que os consumidores se sintam orgulhosos por adquirirem produtos ou contratar serviços de uma empresa com elevada responsabilidade social. Os fornecedores preferem ser parceiros destas empresas. O governo e a sociedade civil tornam-se parceiros da empresa nos seus empreendimentos sociais. Os seus funcionários se sentem orgulhosos e motivados em trabalhar nesta empresa. O que estes benefícios refletem são os ganhos da cidadania empresarial como vantagem competitiva (PORTER; KRAMER, 2006).

Estes investimentos sociais são também manifestações éticas do compromisso com os diversos stakeholders. Sung (1995) descreve a ética de responsabilidade como o levar em conta somente aquilo que é certo dentro de uma esfera particular, sem levar em conta o conjunto de uma ação aparentemente racional em irracional de um ponto de vista mais amplo. Mas, uma empresa socialmente responsável não se limita apenas à prática e a adoção de valores éticos.

Empresas socialmente responsáveis atendem também a cuidados na gestão ambiental (TACHIZAWA, 2002). Os clientes e a comunidade valorizam cada vez mais a proteção ao meio ambiente. O BRDE - Banco Regional de Desenvolvimento do Extremo Sul define Gestão Ambiental como uma conscientização de um conjunto de princípios, valores, atitudes e comportamentos voltados à preservação do meio ambiente e a qualidade de vida do homem, em harmonia com todas as demais espécies. A partir desse raciocínio, cuidados com resíduos recicláveis, água, consumo e descarte são fatores vitais a serem destacados no cotidiano do ambiente familiar, organizacional e também de lazer (TACHIZAWA, 2002). Adotado cada vez mais pelas empresas, o conceito de responsabilidade social e gestão ambiental vêm sendo visto como um indicador de competitividade empresarial que expressa a forma como a empresa interfere nos problemas da sociedade, tendo em vista a melhoria da qualidade de vida e a solução de conflitos sociais direta ou indiretamente relacionados às suas atividades. É, assim, estipulado que organizações que tomem decisões estratégicas integradas à questão ambiental e ecológica provavelmente conseguirão capturar uma vantagem competitiva.

Pelo referencial teórico exposto anteriormente, é de se esperar que:

- Em função da visão moderna dos princípios cooperativistas, as cooperativas sejam organizações independentes e interessadas no desenvolvimento sustentável de suas comunidades. Sendo assim, a responsabilidade social e ambiental seriam aspectos primordiais e importantes no contexto estratégico das cooperativas. (Proposição 1).

- Na atuação em relação ao ambiente de competição, as cooperativas não deixem de relevar as atividades sociais. Assim, em sua operação deveriam ter em conta aspectos relacionados à responsabilidade social e ambiental, incluindo de alguma a atuação de seus cooperados. (Proposição 2)

- As cooperativas são certificadas em relação a normas de responsabilidade social ou ambiental ou estão em processo de certificação. (Proposição 3).

- As cooperativas poderiam participar de ações comunitárias de responsabilidade social, porém, em função de seus princípios, se envolveriam prioritariamente em projetos sociais próprios. Daí, estes projetos deveriam gerar retorno social e de mídia institucional, assim como, existiriam atividades expressas de marketing social. (Proposição 4).

\section{O Estudo de Caso Cocamar}

O presente estudo de caso foi realizado na empresa COCAMAR - Cooperativa Agroindustrial, que atua no segmento de agronegócios, com foco em recebimento, beneficiamento, industrialização e comercialização de soja, milho, canola, algodão, casulos do bicho-da-seda, cana-de-açúcar, café, trigo e frutas, além do fornecimento de insumos agropecuários aos seus cooperados.

A pesquisa é qualitativa e descritiva por ser o melhor modelo para analisar um contexto específico (LÜDKE; ANDRÉ, 1986; VERGARA, 1997; BABBIE, 1998), mas recorrendo também a fatos passados (RICHARDSON et al., 1989). Caracteriza-se como estudo de caso por estar circunscrita a uma organização, no caso a COCAMAR, que é analisada de forma profunda e 
detalhada (GODOY, 1995a, 1995b; VERGARA, 1997; YIN, 2005).

Conforme Eisenhardt (1989), o estudo de casos permite replicar ou estender uma teoria emergente. O caso da COCAMAR foi escolhido pelo seu excelente desempenho administrativo e financeiro, e pelo reconhecimento em relação a ações de responsabilidade social, pelo que tem obtido diversos prêmios. Os dados utilizados foram recolhidos em diversas fontes para possibilitar a triangulação e aumentar a confiabilidade (YIN, 2005). Recorreu-se primordialmente à análise documental, mas complementada por entrevistas a cinco executivos da COCAMAR, tendo estes funções nas áreas da Assessoria Comercial (ACM),
Diretoria Administrativa e Financeira (DAF), Gerência de Integração e Qualidade (GIC), Assistência Social (ASS) e Analista de Responsabilidade Social (ARS). Este último cargo, exclusivamente para analisar os aspectos de RSC da empresa. As entrevistas foram de cunho exploratório e se voltaram para levantar dados , informações e declarações relacionadas às proposições apresentadas ao final do referencial teórico. Os dados secundários foram acedidos com o auxílio do Departamento de Desenvolvimento Humano da COCAMAR, que facilitou os dados de venda, projetos, ações internas etc., além dos dados disponibilizados no site da empresa. A Tabela 4 sumaria os pontos fortes e fracos das diversas fontes usadas neste estudo.

Quadro 4 - Principais fontes de dados no estudo de caso da COCAMAR

\begin{tabular}{|l|l|l|}
\hline \multicolumn{1}{|c|}{ Fonte de evidências } & \multicolumn{1}{c|}{ Pontos Fortes } & \multicolumn{1}{c|}{ Pontos Fracos } \\
\hline $\begin{array}{l}\text { Documentos e registros: acesso a } \\
\text { relatórios internos de planejamento e } \\
\text { desempenho; jornais e outras formas de } \\
\text { fumunicação com o cooperado e }\end{array}$ & $\begin{array}{l}\text { Facilitaram a revisão.. } \\
\text { São fontes de evidências } \\
\text { documentadas.. }\end{array}$ & $\begin{array}{c}\text { Parte destes documentos foram } \\
\text { selecionados pelos gestores. }\end{array}$ \\
\hline $\begin{array}{l}\text { Entrevistas: realizadas com } \\
\text { gestores e técnicos da empresa. }\end{array}$ & $\begin{array}{l}\text { Direcionadas ao tópico. } \\
\text { Forneceram inferências causais } \\
\text { percebidas (perceptiva). }\end{array}$ & $\begin{array}{l}\text { Não foram entrevistados cooperados e } \\
\text { funcionários de níveis mais baixos, o que não } \\
\text { confronta percepção dos gestores e técnicos } \\
\text { diretamente envolvidos nas ações de RSC.. }\end{array}$ \\
\hline $\begin{array}{l}\text { Evidências físicas: existência de } \\
\text { instalações e documentação que } \\
\text { comprova as ações, assim como pelos } \\
\text { prêmios recebidos. }\end{array}$ & $\begin{array}{l}\text { Percepção em relação a } \\
\text { aspectos culturais e operações } \\
\text { técnicas. }\end{array}$ & . \\
\hline
\end{tabular}

Fonte: Os autores a partir de Yin, 2005, p. 13.

\subsection{A COCAMAR: Apresentação}

A COCAMAR foi fundada em 1963 por produtores rurais com a denominação de Cooperativa de Cafeicultores de Maringá. Na sua gênese esteve a dificuldade de os agricultores comercializarem a sua produção, principalmente de café. No final da década de sessenta e até ao presente começa a diversificação para outros produtos agrícolas, tais como algodão em caroço, soja, óleos vegetais, seda, frutos e sucos, etc. A expansão foi gradual atendendo às tendências da agricultura regional e às diretrizes da política agrícola governamental. Atualmente, a cooperativa possui entrepostos localizados no Paraná, Santa Catarina, Rio Grande do Sul, São Paulo, Mato Grosso do Sul, Goiás e Minas Gerais, numa área de ação constituída por mais de 50 municípios. O seu faturamento cresceu para $R \$ 1$ bilhão em 2007 (Quadro 5). A visão da COCAMAR é expressa como "Ser reconhecida como a melhor cooperativa do agronegócio brasileiro".

Quadro 5 - Dados operacionais da COCAMAR
\begin{tabular}{|l|c|c|c|c|c|}
\hline $\begin{array}{c}\text { Capital Social } \\
\text { (milhões) }\end{array}$ & 2003 & 2004 & 2005 & 2006 & $2007^{*}$ \\
\hline $\begin{array}{c}\text { Quadro Funcional } \\
\text { (colaboradores) }\end{array}$ & 3159 & 3368 & 3319 & 2175 & 2175 \\
\hline $\begin{array}{c}\text { Quadro Social } \\
\text { (cooperados) }\end{array}$ & 6527 & 7014 & 6564.6757 .351 & 6721 & 6657 \\
\hline $\begin{array}{c}\text { Faturamento } \\
\text { Anual }\end{array}$ & $\begin{array}{c}920.126 \\
\text { Milhões }\end{array}$ & $\begin{array}{c}1.067 .213 \\
\text { Bilhão }\end{array}$ & $\begin{array}{c}874.40 \\
\text { Milhões }\end{array}$ & $\begin{array}{c}793.105 \\
\text { Milhões }\end{array}$ & 1 Bilhão \\
\hline
\end{tabular}

* Dados estimados para final do ano de 2007.

Fonte: COCAMAR Cooperativa Agroindustrial de Maringá não consta da referência 
Com sede em Maringá, Paraná, a COCAMAR e uma cooperativa de produtores, com aproximadamente 25 mil associados, se utilizando do slogan "da nossa terra para sua mesa", por possuir um rígido controle de qualidade para que o consumidor tenha sempre a sua disposição os melhores produtos. A COCAMAR construiu uma realidade que a distingue em diferentes mercados, em suas declarações, procrando pautar-se pela ética em suas ações e negociações e investindo de forma considerável em pesquisas.

\subsection{Antecedentes Estratégicos da COCAMAR}

Inocêncio e Machado-da-Silva (2001) analisaram a evolução do posicionamento estratégico da COCAMAR no período de 1993 a 1999 em relação aos valores e crenças de seus dirigentes. Neste período houve mudanças no posicionamento estratégico da COCAMAR, impulsionadas pela crise financeira da empresa e o dilema em relação às suas características e objetivos como organização cooperativa. Estas mudanças são sumariamente indicadas no Quadro 6.

Quadro 6 - Reposicionamento estratégico e de valores da COCAMAR: 1993 a 1999

\begin{tabular}{|c|c|c|c|}
\hline \multicolumn{2}{|c|}{ Posicionamento Estratégico } & \multicolumn{2}{|c|}{ Valores/Crenças dos Dirigentes } \\
\hline $\begin{array}{c}\text { Antes da Crise } \\
\text { (de } 1993 \text { a 1995) }\end{array}$ & $\begin{array}{l}\text { Depois da Crise } \\
\text { (de } 1995 \text { a 1999) }\end{array}$ & $\begin{array}{l}\text { Antes da Crise } \\
\text { (de } 1993 \text { a 1995) }\end{array}$ & $\begin{array}{l}\text { Depois da Crise } \\
\text { (de } 1995 \text { a 1999) }\end{array}$ \\
\hline $\begin{array}{l}\text { Basicamente } \\
\text { Interno }\end{array}$ & $\begin{array}{l}\text { Mercado Interno, com foco no } \\
\text { mercador regional } \\
\text { Intensificação das vendas no } \\
\text { varejo }\end{array}$ & Pioneirismo & Parceria \\
\hline $\begin{array}{l}\text { Diversificação das opções } \\
\text { ao produtor }\end{array}$ & $\begin{array}{l}\text { Ampliação da linha de } \\
\text { produtos já existentes }\end{array}$ & Modernidade & Profissionalização \\
\hline $\begin{array}{l}\text { Moderadas reduções de } \\
\text { custos administrativos }\end{array}$ & $\begin{array}{l}\text { Intensivas reduções de } \\
\text { custos gerais }\end{array}$ & Ousadia & Planejamento \\
\hline Grandes investimentos & Moderação nos investimentos & Investimentos & Custos \\
\hline Foco no social & Foco na empresa cooperativa & Política Social & Política Econômica \\
\hline
\end{tabular}

Fonte: Inocêncio e Machado-da-Silva (2001)

A crise iniciada em 1995 leva a empresa a alterar os seus valores e crenças. A crise afugentou vários fornecedores e os processos trabalhistas afetaram a confiança dos associados e a própria legitimidade da COCAMAR. A perda da confiança na competência dos executivos da COCAMAR foi ultrapassada com a profissionalização da gestão (líder e equipe executiva) e maior foco na eficiência operacional (INOCÊNCIO; MACHADO-DA-SILVA, 2001; SILVESTRE; CRUBELLATE, 2007). Aspectos de sucessão e profissionalização são críticos para o desempenho sustentável das empresas (SERRA;
FIATES; FERREIRA, 2007). Passaram a preponderar aspectos ligados aos resultados financeiro e, como Inocêncio e Machado-da-Silva (2001) argumentam, a cooperativa passou a ter maior cuidado na alocação e desenvolvimento de recursos. O repensar da COCAMAR também levou ao questionar dos valores básicos do cooperativismo, conotado com aspectos sociais, trabalhando de forma assistencialista com o cooperado e preocupada com o desenvolvimento regional (SILVESTRE; CRUBELLATE, 2007). A nova filosofia de gestão é mais baseada em valores típicos de organizações privadas, mas há vestígios vincados da preservação de valores antigos (ver Quadro 7). 
Quadro 7 - Valores culturais predominantes entre os gestores da COCAMAR (1990-2005)

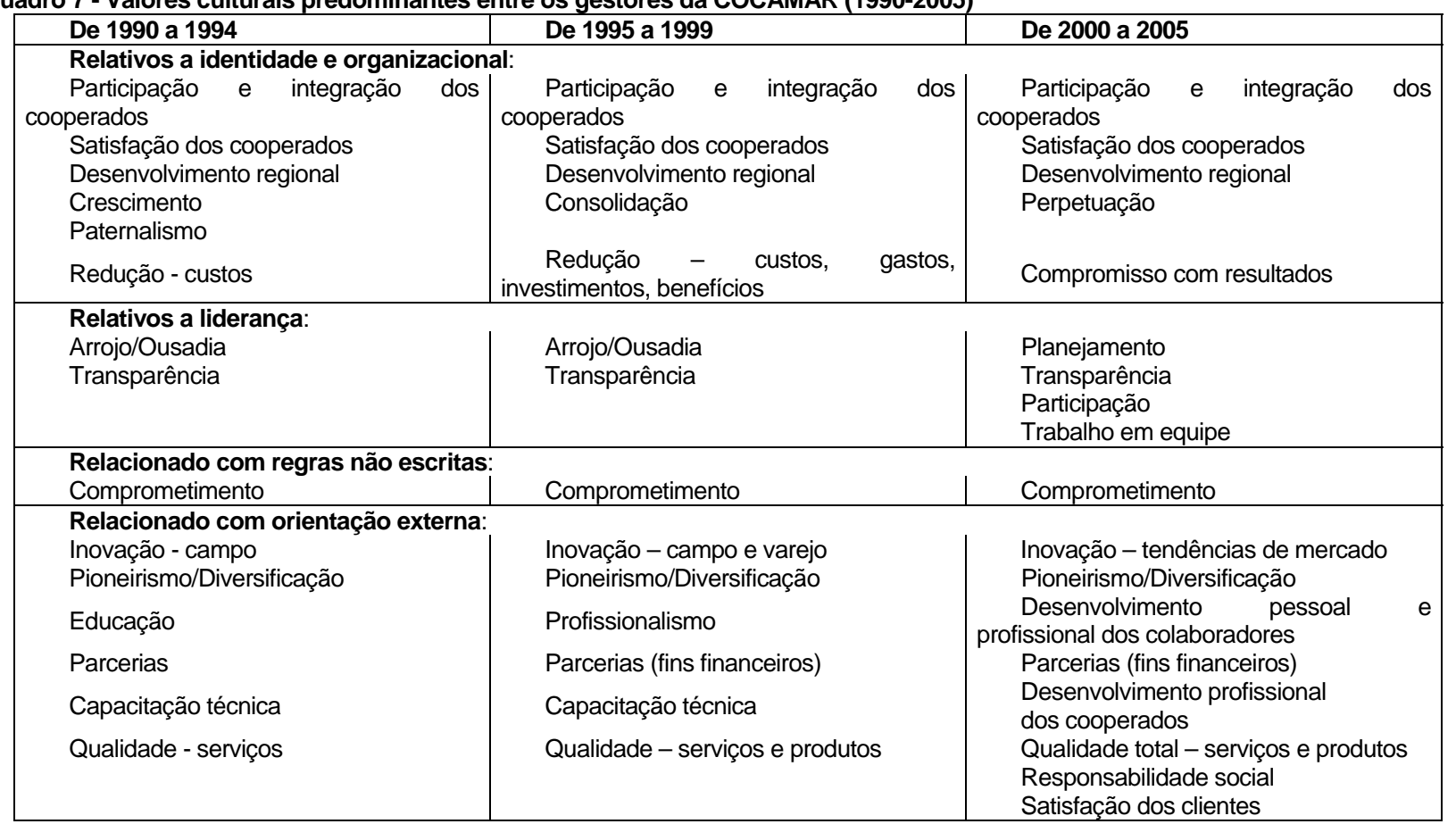

Fonte: Silvestre e Crubellate, 2007.

A utilização de planejamento estratégico, a avaliação periódica dos resultados de projetos e investimentos, as mudanças na estrutura hierárquica e reestruturação do quadro funcional incentivando o trabalho em equipe, e o foco na responsabilidade social, fizeram parte do turnaround da COCAMAR (Quadro 8). Por exemplo, a nível organizacional, foi criada uma estrutura interna dedicada exclusivamente ao desenvolvimento de programas e projetos sociais e ambientais que abrangem todas as comunidades nas regiões de atuação da cooperativa e as ações ligadas a melhoria das condições de vida e à preservação do meio ambiente. A COCAMAR começou a ser reconhecida como organização cidadã.

\begin{tabular}{|c|c|}
\hline $\begin{array}{c}\text { VALORES } \\
\text { INCREMENTADOS }\end{array}$ & MUDANÇAS INTERNAS \\
\hline $\begin{array}{l}\text { Trabalho em equipe } \\
\text { Participação }\end{array}$ & $\begin{array}{l}\text { Mudanças Administrativas: } \\
\text { - Criação do grupo de gestores; } \\
\text { - Mudança na estrutura hierárquica; } \\
\text { - Reestruturação do quadro de colaboradores; } \\
\text { - Elaboração do planejamento estratégico }\end{array}$ \\
\hline Responsabilidade social & $\begin{array}{l}\text { Mudanças Mercadológicas: } \\
\text { - Adoção de programas e projetos sociais e ambientais. }\end{array}$ \\
\hline Satisfação dos clientes & $\begin{array}{l}\text { Mudanças Mercadológicas: } \\
\text { - Adoção de um programa de Qualidade total; } \\
\text { - Melhoria canal de comunicação } \\
\text { - Investimento na área de marketing, visando solidificação da marca; } \\
\text { - Ampliação dos canais de comercialização; } \\
\text { - Investimentos na área industrial. }\end{array}$ \\
\hline
\end{tabular}

Fonte: Silvestre e Crubellate, 2007.

A ideologia central e a missão da COCAMAR são apoiadas num conjunto de princípios fundamentais (Quadro 9). Ao avaliar a missão da COCAMAR, o último item - "Ser uma organização cidadã e promotora do desenvolvimento regional." - está relacionado com o sétimo princípio cooperativista. Este princípio também se reflete nos valores da COCAMAR "Ética e Cidadania" e "Desenvolvimento Regional". 
Quadro 9 - Elementos da ideologia central e da missão da COCAMAR

Missão da COCAMAR

- $\quad$ Prover de satisfação o cooperado, oferecendo serviços e produtos com qualidade e eficiência, preservando os parâmetros de rentabilidade.

- $\quad$ Ser reconhecida por clientes e fornecedores como uma organização comprometida com a qualidade.

- Buscar perpetuação da organização a partir da otimização de sua estrutura operacional e industrial.

- $\quad$ Manter seus colaboradores aptos a cumprirem suas funções com segurança, orgulho e motivação.

- Ser uma organização cidadã e promotora do desenvolvimento regional.

Valores da COCAMAR

- Satisfação dos cooperados e clientes

- Qualidade dos produtos e serviços

- $\quad$ Otimização da estrutura;

- $\quad$ Desenvolvimento Pessoal e Profissional dos colaboradores e cooperados;

- $\quad$ Ética e Cidadania;

- Desenvolvimento Regional;

- Perpetuação;

- Compromisso com resultado.

Visão da COCAMAR

- Ser reconhecida como a melhor cooperativa do agronegócio brasileiro.

Ficou evidenciado nas entrevistas que no planejamento estratégico e no BSC a COCAMAR trata especificamente de ações sociais e ambientais. O planejamento estratégico foi uma importante ferramenta para a consolidação da COCAMAR, conforme Silvestre e Crubellate (2007). Conforme entrevista com o DAF:

[...] a cooperativa desenvolve seu planejamento estratégico a cada cinco anos, fazendo assim anualmente revisões e planos orçamentários para cada período. Houve uma reestruturação do planejamento estratégico no ano de 2005, onde a cooperativa passou a utilizar o BSC (Balanced ScoreCard), implantado e acompanhado pela FGV Fundação Getulio Vargas. Dentro desta metodologia a cooperativa possui um planejamento especifico para as ações ambientais e outro para as sociais, que foi elaborado em 2005 e com projeções ate o ano de 2010.

Estas constatações confirmam, na COCAMAR, a Proposição 1, visto que, a responsabilidade social e a ambiental continuam a ser aspectos fundamentais da estratégia, mesmo após as mudanças de posicionamento de crenças e valores (SILVESTRE; CRUBELLATE, 2007).

\subsection{Projetos Sociais Internos e Externos}

A COCAMAR desenvolveu um conjunto alargado de programas de responsabilidade social e ambiental para atender seu público interno (colaboradores e familiares) e também o público externo (comunidade onde está inserida) (Quadro 10). Por exemplo, da entrevista com a ASS, podese constatar a preocupação com os colaboradores e familiares. Esta é manifesta na realização de visitas periódicas aos colaboradores nos vários entrepostos da cooperativa, aconselhando e acompanhando atividades e reclamações dos colaboradores. A ASS sustenta a preocupação também com a qualidade de vida da família de seus colaboradores, comentando que o colaborador estará mais disposto para o trabalho e produzir/trabalhar de forma mais contente sabendo que sua família está bem.

Quadro 10 - Projetos sociais internos e externo da COCAMAR
\begin{tabular}{|c|l|}
\hline PÚBLICO ALVO & \multicolumn{1}{c|}{ PROJETOS SOCIAIS } \\
\hline INTERNO & $\begin{array}{l}\text { Programa Vivo Melhor, Centro de Estudos COCAMAR, Coral e Orquestra, Suco Justo, } \\
\text { Programa Voluntariado, Cozinha Experimental. }\end{array}$ \\
\hline & $\begin{array}{l}\text { Programa Voluntariado, Revitalização de Escolas, Campanha Solidaria, Escola de } \\
\text { Futebol, Coral Vozes do Coração, Programa Banco de Talentos, Fruticultura, Trainee } \\
\text { EXTERNO }\end{array}$ \\
& $\begin{array}{l}\text { Pdministrativo para Pessoas com Deficiência, Programa Jovem Aprendiz Cooperativo, } \\
\text { Atividades Agropecuária na Pequena Propriedade, Cozinha Experimental, Programa } \\
\text { Escola no Campo, Programa Cooperjovem, COCAMAR Ecológica. }\end{array}$ \\
\hline
\end{tabular}

Fonte: Os autores

Dentre os atendimentos realizados pela ASS, podem ser citados os de ordem financeira, relacionamento familiar, saúde, acidentes, problemas particulares, dentre outros.
Curiosamente, tanto a ARS como o DAF afirmaram que a prioridade da cooperativa em se tratando de responsabilidade social está voltada para o público interno. A nível das ações ambientais, sob a 
responsabilidade do GIC, a cooperativa possui projetos de responsabilidade ambiental internos (ex.: tratamentos de efluentes, recursos não renováveis e resíduos sólidos) e externos (por vezes em parceria com outras organizações). Segundo o GIC a cooperativa se utiliza da ISO 14000 na área ambiental, da SA 8000 para as ações sociais, e da certificação para segurança de alimentos (APPCC) voltada para a exportação de ração.

Quanto à exportação também foi entrevistado o ACM que cuida das negociações de suco concentrado, voltadas para o mercado interno e externo. O ACM comentou que a cooperativa possui uma parceria com uma ONG Européia denominada Fairtrade Labelling Organization FLO, que atua em 21 países trabalhando dentro de uma filosofia de mercado solidário, e a COCAMAR é sua parceira aqui no Brasil. Esta parceria visa uma melhor e mais justa qualidade de vida aos catadores de laranja. Com esta parceria a cooperativa é certificada FLO e consegue penetrar em alguns países onde é obrigatória esta certificação pra que possa fazer negócios.

A preocupação com o público interno, externo e parceiros é explicita na COCAMAR quando podese analisar seus programas de Responsabilidade Social e Ambiental. Questionado sobre os valores investidos em projetos de responsabilidade social e ambiental, o DAF comentou que foram investidos em responsabilidade social até $1 \%$ do faturamento da cooperativa e nos projetos ambientais aproximadamente $0.025 \%$ do faturamento bruto.

$\mathrm{Na}$ COCAMAR foram identificados diversos programas relacionados às atividades sociais como foi previsto a partir do referencial teórico (ver as Proposições 1 e 2). Estes programas são voltados para o público interno e externo. Aparentemente, sobretudo nos programas ambientais, a empresa parece envolver os cooperados.

Um aspecto relevante e que reforça estas duas proposições, é o fato de, em seu organograma existir a COCAMAR Social, voltada exclusivamente para as ações sociais da cooperativa.

Vale observar que apesar das pressões para aumentar a competitividade, conforme Inocêncio e Machado-da-Silva (2001), a COCAMAR investe fortemente em ações de responsabilidade social e ambiental, também confirmado por Silvestre e Crubellate (2007). Como qualquer organização, as cooperativas devem ser sustentáveis operacionalmente e economicamente para viabilizar suas ações de responsabilidade social e ambiental adicionais, visto que a própria operação da cooperativa já está ligada a proporcionar rendimento adequado e justo aos seus cooperados. Estas constatações também coincidem com os resultados de Silvestre e Crubellate (2007) nos resultados do período de 2000 a 2005.

\subsection{Reconhecimento em Relação à Responsabilidade Social e Ambiental}

Vários prêmios e distinções reconhecem o trabalho da COCAMAR em relação às ações e projetos desenvolvidos junto à comunidade interna e externa em matéria de excelência em gestão social e ambiental. De entre estas distinções salienta-se: o Prêmio Valor Social 2004, do Jornal Valor Econômico, na categoria "Respeito ao Meio Ambiente", consagrando o trabalho desenvolvido pela Cooperativa na área de responsabilidade ambiental; o Prêmio Expressão de Ecologia 2004, da Revista Marcas de Expressão, graças ao Marketing Ecológico adotado pela cooperativa; o Prêmio Cooperativa do Ano 2005, na categoria Meio Ambiente (OCB / Revista Globo Rural) pelo trabalho da COCAMAR Ecológica na educação da sociedade para um desenvolvimento sustentado; o Prêmio Cooperativa do Ano 2007, na categoria Gestão Meio Ambiente (OCB / Revista Globo Rural) pela sua colaboração no "Projeto Cultivar"; o Prêmio Cooperativa do Ano 2007, na categoria Gestão Profissional (OCB / Revista Globo Rural), pela implementação do projeto "Planejamento Estratégico Participativo"; além de várias menções em revistas (ver por exemplo REVISTA EXPRESSÃO, 2008; LOURENÇO, 2005) da especialidade em matérias como a responsabilidade social, excelencia de gestão, melhoria nos processos produtivos, pelas ações direcionadas para a garantia de direitos básicos, combate ao trabalho infantil e educação ambiental. Demonstra-se, assim, que a COCAMAR incorpora na sua estratégia de negocios a responsabilidade pelos problemas ambientais e sociais.

Dessa forma, quando questionados, todos os entrevistados concordaram que estas ações de Responsabilidade Social e Ambiental acabam refletindo positivamente na conquista de novos mercados, potencializando assim seus negócios $A$ ARS finalizou dizendo que as ações de Responsabilidade Social e Ambiental agregam valor a marca, e que no Brasil ainda não se tem a cultura de adquirir um produto porque a empresa produtora desenvolve ações de responsabilidade social, mas quem sabe num futuro próximo haverá a possibilidade de associar as ações de responsabilidade social como elemento de reconhecimento por parte dos consumidores.

A Proposição 4 argumenta que as cooperativas envolvem-se prioritariamente em projetos sociais 
próprios e que estes projetos devem gerar retorno social e de mídia institucional, existindo atividades expressas de marketing social. Embora a COCAMAR se envolva prioritariamente com projetos sociais próprios, e estes tenham gerado bastante retorno social e mídia institucional, representados pelos diversos prêmios mencionados, não existem atividades expressas de marketing social. Ou seja, poderia ser uma oportunidade, mas somente a primeira parte da proposição está em acordo com o que foi observado.

A COCAMAR se enquadra nas quatro dimensões para a responsabilidade social, sugeridas Carrol (1991) e descritas a seguir. Quanto às dimensões econômicas e produtiva e lucrativa, atendendo a expectativa dos cooperados em relação ao desempenho financeiro. Em relação a dimensão legal, e pelas certificações que possui, respeita as leis e os regulamentos. Em relação à dimensão ética, respeita a todos os princípios e padrões que definem a conduta aceitável em relação a todos os intervenientes, assim como nas tomadas de decisão.

As observações acima reforçam que a COCAMAR utiliza-se de critérios de excelência e que se posiciona no mesmo nível das organizações líderes em relação à responsabilidade social e ambiental, o que concorda com a Proposição 3.

\section{Discussão e Notas Finais}

A gestão empresarial não é dissociável da sua atuação e papel social. Se, por um lado, as atividades capitalistas podem provocar desastres (por exemplo, ambientais), por outro lado, as empresas que demonstram ter uma gestão pautada pela responsabilidade social geram uma sinergia positiva em que tanto elas como a sociedade beneficiam. Empresas competitivas devem, hoje, combinar a produtividade e lucratividade com a sua postura a longo prazo. O contrato social entre as empresas e a sociedade está em constante mudança pelo que a busca por competitividade deve estar integrada com práticas sociais compromissadas.

A difusão do conceito de responsabilidade social como uma extensão do papel da empresa, faz que esta seja vista como co-responsável pela promoção do desenvolvimento e bem-estar da sociedade envolvente. Isto requer um relacionamento ético e transparente com os stakeholders, o respeito pelo meio ambiente e a promoção dos interesses da sociedade. O caso estudado da cooperativa COCAMAR ilustra como uma organização pode incluir a responsabilidade social nos seus objetivos estratégicos.

Neste estudo foi descrito um estudo de caso de Empresa Ética e Socialmente Responsável numa organização do setor de Agribusiness, mais especificamente na COCAMAR - Cooperativa Agroindustrial de Maringá. Foi apresentado como a responsabilidade social corporativa se insere na estratégia da COCAMAR. Neste caso, percebeu-se que a cooperativa passou por dificuldades financeiras na década de 90, que a levaram a avaliar seu posicionamento, crenças e culturas (INOCÊNCIO; MACHADO-DA-SILVA, 2001).

No estudo de caso foi verificado que a COCAMAR, tem a responsabilidade social e ambiental como um dos aspectos primordiais para a empresa. Também, apesar da competição acirrada e de fases difíceis ao longo da existência da empresa, manteve suas ações de responsabilidade social e as incentivou junto aos cooperados. A COCAMAR participa de ações comunitárias de responsabilidade social, mas possui projetos sociais próprios. Entretanto, a cooperativa ainda só possuía intenção em relação a certificação relacionadas à normas ligadas à RSC,e não possui intencionalmente ações de marketing relacionadas à RSC.

Investigação futura pode desenvolver-se ao longo de várias linhas de pesquisa. Porquanto neste trabalho foi realizado com o estudo de um caso de uma considerada pela sua excelência, seria importante desenvolver trabalhos empíricos com amostras grandes para reforçar a capacidade preditiva e de generalização de como as empresas podem beneficiar da adoção de práticas social e ambientalmente responsáveis.

Uma das principais implicações teóricas deste artigo é a de procurar relacionar os fundamentos ligados à gênese de uma cooperativa, a uma necessidade de coerência em relaçao aos aspectos sociais e ambientais, inclusive como elementos fundamentais a serem considerados na formulação e na gestão da estratégia, apesar de concentrar-se em um só caso, na visão deste artigo, relevante. Para os gestores, este estudo apresenta, por intermédio de um estudo de caso, como a responsabilidade social e ambiental pode ser importante para a longevidade, reputação e para a capacidade de competir face às crescentes exigências governamentais e da população. 


\section{Referências}

ALENCAR, E. Introdução à metodologia da pesquisa. Lavras: UFLA/FAEPE, 2000.

ALEXANDER, J. C. A importância dos clássicos. In: Teoria social hoje. GIDDENS, A.; TURNER, J. (orgs.). São Paulo: UNESP, 1999.

BOWRING, M. A. De/constructing theory a look at the institucional theory that positivism built. Journal of management inquiry, v. 9, n. 3, September 2000, p. 258-270.

CAVALCANTI, C. Desenvolvimento e natureza: estudos para uma sociedade sustentável. São Paulo: Cortez, 1995

EHLERS, E. M. Agricultura sustentável: origens e perspectivas de um novo paradigma. 2. ed. Guaíba: Agropecuária, 1999.

FERREIRA, L. da C.; FERREIRA L. da C. Limites ecossistêmicos: novos dilemas e desafios para o Estado e para a sociedade. In HOGAN, D. J.; VIEIRA, P. F. (Orgs.). Dilemas socioambientais e desenvolvimento sustentável. 2. ed. Campinas: Ed. da UNICAMP, 1995.

GIL, A. C. Métodos e técnicas de pesquisa social. 5. ed. São Paulo: Atlas, 2007.

LAVILLE, C.; DIONNE, J. A construção do saber: manual de metodologia da pesquisa em ciências humanas. Porto Alegre: Artes Médicas; Belo Horizonte: UFMG, 1999.

LIMA, F. R., RIBEIRO, A. G. Alternativas sustentáveis para a redução da vulnerabilidade socioeconômica e ambiental da agricultura familiar na região do cerrado mineiro: os casos de Uberlândia e Patrocínio. In: II Simpósio Regional de Geografia: "Perspectivas para o Cerrado no Século XXI", Uberlândia, 2003.

MACHADO-DA-SILVA, C.; GONÇALVES S. A. Mudança organizacional, esquemas interpretativos e contexto institucional: dois casos ilustrativos.

Revista de estudos organizacionais. Maringá, v. 1, n. 2, p. 1-16, jul. 2000.

MARCONI, M. A.; LAKATOS, E. V. Fundamentos de metodologia científica. 5. ed. São Paulo: Atlas, 2003.

MDA/CONDRAF. Diretrizes para o

desenvolvimento sustentável. Ministério do desenvolvimento agrário. DF: Brasília, 2006.

$\mathrm{PECl}, \mathrm{A}$. A nova teoria institucional em estudos organizacionais: uma abordagem crítica. IN: Anais do XXIX Enanpad, 2005, Brasília, DF, 18-21 Setembro.

SACHS, I. Desenvolvimento includente, sustentável, sustentado. Rio de Janeiro: Garamond, 2004.
SILVA, L. L. O papel do Estado no processo de ocupação das áreas de cerrado entre as décadas de 60 e 80. Uberlândia: Caminhos de geografia Revista On-Line, 1(2), p. 24-36, dez./2000.

SILVA, C. L. da; MENDES, J. T. G. Reflexões sobre o desenvolvimento sustentável: agentes e interações sob a ótica multidisciplinar. Petrópolis: Vozes, 2005.

TOLBERT, P. S., ZUCKER, L. G. A institucionalização da teoria institucional. In: Handbook de estudos organizacionais: modelos de análise e novas questões em estudos organizacionais. v. 1. p. 194-217. São Paulo: Atlas, 2006.

VASCONCELOS, V. F., SANTOS, R. J. dos. A chegada do projeto PRODECER-I em Iraí de Minas e os migrantes. In: Il Simpósio Regional de Geografia: "Perspectivas para o Cerrado no Século XXI", Uberlândia, 2003.

VIOLA, E. J.; LEIS, H. R. A evolução das políticas ambientais no Brasil, 1971-1991: do bissetorialismo preservacionista para o multissetorialismo orientado para o desenvolvimento sustentável. In HOGAN, D. J.; VIEIRA, P. F. (Orgs.). Dilemas socioambientais e desenvolvimento sustentável. 2. ed. Campinas: UNICAMP, 1995.

ZONEAMENTO ECOLÓGICO-ECONÔMICO DO BAIXO RIO PARANAÍBA: Subsídios técnicos. Relatório Final. Brasília: MMA/SDS, 2002.

ZONEAMENTO ECOLÓGICO-ECONÔMICO DO ESTADO DE MINAS GERAIS (ZEE-MG).

Relatório. Lavras: Editora UFLA, 2008. 